tion is possible, or by reconstructive surgery if the skill is available.

Douglas Roy

Professor of Surgery,

Queen's University,

Belfast BT12 6BJ

I Cooper MJ, Williamson RCN. Splenectomy: indications, hazards and alternatives. $\mathrm{Br}$ f Surg

Fitzpatrick JEP, Kennedy C, McGeown MG, Oreopoulus DG, Robertson JH, Soyannwo MAO Human case of piroplamosis (babesiosis). Nature 1968;217:861-2.

Garnham PCC. Human babesiosis: European aspects. Trans $R$ Soc Trop Med Hyg 1980;74:153-5. Lanet $1977 ;$;i: $127-9$.

Okiye $\mathrm{FD}$, Zeincke $\mathrm{H}$, Engen $\mathrm{DE}$, et al. Splenectomy in high risk primary renal transplant recipients. Am I Surg 1983;146:594-601.

6 Joseph TP, Wyllie GG, Savage JP. The non-operative management of splenic trauma. Aust NZ J Surg 1977;47:179-82.

\section{Management of spontaneous pneumothorax}

To drain or not to drain is the question often posed by the patient who presents with a spontaneous pneumothorax. If the pneumothorax is small (less than 20\%) and asymptomatic it may be treated conservatively on an outpatient basis-provided that the patient returns to hospital immediately if he develops breathlessness. Similarly, most people agree that active intervention with the insertion of an intercostal tube and drainage through an underwater seal is essential for patients with a tension pneumothorax and for pneumothoraces complicated by breathlessness or by an appreciable haemothorax or pyothorax.

Patients with a pneumothorax who fit neither of these categories form an important subgroup, and their management remains controversial. The conservative would argue that most large asymptomatic pneumothoraces will reexpand spontaneously over three to four weeks,' thereby avoiding the need for drainage through an intercostal tube, which is uncomfortable, needs to be left in position for an average of four days, ${ }^{2}$ and carries hazards. ${ }^{2}$ The activist (probably in the majority nowadays) would argue that tube drainage avoids prolonged inpatient and outpatient medical supervision and reduces time off work. Simple aspiration fell into disfavour because of anxieties about laceration of the lung by metal needles, but it has recently been revived successfully with the use of a Teflon intravenous cannula. ${ }^{34}$

My personal experience confirms the view that this is a simple and atraumatic way of dealing with this group of patients. The air is gently aspirated from the pneumothorax through the Teflon cannula with a $60 \mathrm{ml}$ syringe and a plastic three way tap and is expelled under water. Aspiration is stopped when resistance is felt. If four litres is aspirated with no resistance an $x$ ray film will usually confirm that no expansion has taken place, indicating that the pneumothorax is open and needs drainage through an intercostal tube. Complete aspiration without recurrence was achieved in 16 of the 23 cases reported in the two series.

Thus a group of patients with a large pneumothorax, in whom tube drainage is unnecessary, may be treated readily by simple aspiration, and this method further identifies a group in whom the pneumothorax is open and who are likely to benefit from more aggressive treatment with tube drainage and suction. The use of suction is another controversial aspect of management, ${ }^{25}$ although some of the controversy may stem from its use in cases where it is not required-for example, for a closed pneumothorax, where simple aspiration or tube drainage without suction is sufficient to re-expand the lung. Proponents of the technique believe that for patients with an open pneumothorax, suction seals the leak more rapidly by opposing the pleural surfaces. Once it is started suction should continue uninterrupted until expansion is complete and has been maintained for 24 hours. In my view, failed treatment is often due to inappropriate interruption of suction-for example, by clamping off the intercostal drain during nursing procedures or visits to the $x$ ray department.

Finally, definitive surgical treatment is required when tube drainage and suction have been unsuccessful and when, in effect, a bronchopleural fistula has formed. Furthermore, given a recurrence rate of $10 \%$ to $25 \%$, surgical prophylaxis is usually indicated after a second ipsilateral or a first contralateral recurrence, and after the initial event if the patient's lifestyle is such that a recurrence might be life threatening or highly inconvenient. In younger patients with a simple pneumothorax pleurectomy is the prophylactic procedure of choice, with a very low recurrence rate. ${ }^{67}$ In older patients with severe chronic airflow obstruction, chemical pleurodesis with talc, dextrose, or another irritant is safer but less effective.

J F RIORDAN

Consultant Physician in Thoracic Medicine,

Central Middlesex Hospital,

London NW10 7NS

Stradling P, Poole G. Conservative management of spontaneous pneumothorax. Thorax 1966; 21:145-9.

ontaneous pneumothorax: suction or no suction, early or late removal? Thorax 1982;37:46-8.

Raja OG, Lalor AJ. Simple aspiration of spontaneous pneumothorax. $\mathrm{Br}$ f Dis Chest 1981; 75:207-8

${ }^{4}$ Hamilton AAD, Archer GJ. Treatment of pneumothorax by simple aspiration. Thorax 1983;

Klassen KP, Meckstroth CV. Treatment of spontaneous pneumothorax. Prompt expansion with

aensler EA. Partial pleurectomy for recurrent spontaneous pneumothorax. Surg Gynecol Obstet

Raj Behl P, Holden MP. Pleurectomy for recurrent pneumothorax. Chest 1983;84:785.

\section{How might we improve surgical services for rural populations in developing countries?}

Any doctor who has worked in a developing country will not easily forget the widespread and pathetic evidence of surgical neglect in the villages. Huge hernias and hydroceles, unsightly lumps on the faces of women and children, and compound fractures infested with maggots bear testimony to the failure of so many countries to provide even a basic level of surgical care to their people.

Is it possible in countries where the expenditure on health is just over £1 per person a year to provide the rural population with a more comprehensive surgical service?' Probably the answer is yes-but only with a more rational use of existing resources, discarding unimaginative, inefficient, and inappropriate systems of health care delivery. We must first stop building ever more costly but politically rewarding large showpiece "disease palaces" in the big cities" to which only $20 \%$ of the population has access, ${ }^{3}$ and divert much of our material and medically trained manpower to the villages. Two important papers suggest how this might be done. 
Nordberg puts the need into a clearer perspective ( $p$ 92), estimating that in rural east Africa only one patient in seven with the fairly simple and common surgical problem of a strangulated hernia actually has an operation performed. ${ }^{4}$ What happens to the others? They probably die or develop some ghastly complication such as an intestinal fistula, rendering them incapacitated for life. The important question is why these patients did not have an operation performed at an earlier stage. They may have been unaware of the benefits of surgery - or they may have been dissatisfied with the kind of medical care offered locally - anything remotely "surgical" being referred automatically to a large and distant city disease palace.

Even patients who are brave, rich, and fit enough to make the journey experience a culture shock in a huge concrete jungle where they are jostled by crowds of people, have to fill in unintelligible forms, and on reaching the strange doctor to whom they are referred may be met with an officious and unsympathetic attitude. This overworked hospital surgeon has to deal with an unending number of what he sees as trivial problems. He often believes that his talents and training are better suited to cope with more complicated and intellectually stimulating and challenging cases. The doctor sends the villager for so called routine investigations in yet other hospital departments. Finally, after three or more separate hospital visits over two weeksduring which food and accommodation have to be found in a strange city - the patient with an unstrangulated hernia is put on a long waiting list for operation. Small wonder that neither he nor his neighbours are willing to go through this sort of experience again.

A second paper, by Gil et al, ${ }^{5}$ describes how a more efficient and accessible system of surgical care might be organised. Firstly, they showed that three quarters of the operations done in a large district in Colombia, South America, were of low levels of complexity and could easily be performed by doctors with a fairly rudimentary training in surgery using local or spinal anaesthesia in a simple operating theatre with little equipment. Furthermore, the patient could be sent home after the operation. The infection rate was $0.5 \%$, and $95 \%$ of the patients were satisfied. ${ }^{6}$ The Colombian workers also found that despite the great demand for surgical services ( $2 \%$ of the population in Colombia have a surgical problem every year) both the operating rooms and the well trained surgeons were underused and ill organised. Ambulatory surgery alone might have freed 100000 bed occupancy days in a single year.

These and other data show that surgical care for rural populations in developing countries should be restructured into two basic categories: the mobile and the static. ${ }^{78}$ The mobile type-using large ambulances with operating theatre facilities, such as the Chitteranjan mobile hospitals in Kashmir" or the better known flying doctor services-could be used in areas where the population is scattered, communications are difficult, and trained personnel are in short supply. This type of service would, however, be very expensive and beyond the resources of most countries in the Third World. An alternative mobile but low cost surgical service is the cataract or tubectomy camp, where these operations are done in tents by surgeons who visit the area at regular intervals.

The static type of service might be based on a graded three tier health care delivery structure that already exists in many countries - broadly the peripheral primary health centre, the district hospital, and the academic medical institution. ${ }^{1011}$ But important changes need to be made in personnel and in emphasis.

The primary health centre might be manned by a new kind of doctor admirably described as a specialist district physician. ${ }^{12} \mathrm{He}$ or she could not only deal with basic problems in internal medicine, paediatrics, and obstetrics but could also repair a hernia, perform a caesarean section, set simple fractures, and deal with other injuries. One quarter of the more complicated surgical problems would need to be referred to the district hospital. He would attain this limited degree of surgical competence by a much shorter period of postgraduate surgical training than the conventional five years. ${ }^{13}$

Saved from dealing with the minor problems that take up most of their time at present, the surgeons at the district hospital could concentrate on improving the standard of care for their patients needing cholecystectomy, prostatectomy, hysterectomy, and gastrectomy. They could also make regular visits to the primary health centre to help the local doctor and follow up their own postoperative patients who have been sent back early to a local health centre nearer their home to convalesce.

This would leave the academic medical institutions to make better use of their skills and the expensive high technology available to them and concentrate on providing care for problems in cardiothoracic surgery, neurosurgery, and the difficult cases which have been referred to them from the district hospital. They could also change the type of training they provide to their students to meet the needs of the new health system.

Finally, the academic institutions should also change the orientation of their research from publishing case reports or duplicating Western studies to investigating the surgical problems in their own countries. ${ }^{14}$ These could include developing simple, low cost methods of management that could be carried out in a primary health centre-managing compound fractures with antibiotics and dressings $\mathrm{s}^{15}$ or using noradrenaline gastric lavage to control upper gastrointestinal bleeding. ${ }^{16}$ They could evaluate the use of costly methods of investigation of little proved value such as the routine preoperative chest $x$ ray examination, ${ }^{17}$ and assess scientifically the effects of indigenous methods of treatment.

Health care problems in developing countries have largely meant the control of infection and malnutrition. The time has come to devote a little more attention to the not inconsiderable problem of surgical disease.

SAMIRAN NUNDY

Associate Professor of Surgery,

All India Institute of Medical Sciences,

New Delhi 110029 ,

India

${ }^{1}$ Ministry of Health and Family Welfare. Pocket book of health statistics of India. New Delhi Central Bureau of Health Intelligence, Directorate General of Health Services, 1983.

Morley D, Woodland M, eds. Background to the use of growth charts. In: See how they grow. London and Basingstoke: Macmillan Press Ltd, 1979:20.

Census Commissioner of India. Census of India 1981. Series 1. Paper 2. Part IIB(ii). New Delhi Registrar General and Census Commissioner of India, 1981

Belcher DW, Nyane PK, Wurapa FK. The prevalence of inguinal hernia in adult Ghanaian males. Trop Geogr Med 1978;30:39-43.

Gil AV, Galarza MT, Guerrero R, Pardo de Velez G, Peterson OL. Surgeons and operating rooms: underutilised resources. Am f Public Health 1983;73:1361-5.

Echeverri O, Manzano C, Quintero M, Cobo A. Postoperative care: in hospital or at home, a feasibility study. Int I Health Sero 1972;2:101-10.

endrickse RG. Paediatrics. Discussion of technologies for rural health. Proc R Soc Lond 1977;

Barker EA. Surgical techniques and priorities. Discussion of technologies for rural health. Proc $R$ Soc Lond 1977;199:69-72.

Park JE, Park K, eds. Health planning and management. In: Textbook of preventive and social medicine.7th ed. Jabalpur: Banarisidas Bhanot, 1981:677.

${ }_{10}^{10}$ Hsiao WC. Transformation of health care in China. $N$ Engl f Med 1984;310:932-6.

1 Ubell RN. High tech medicine in the Caribbean. $N$ Engl $\mathcal{Y}$ Med 1983;309:1468-72.

2 Roy AD. Surgical care in the village. Proc $R$ Soc Lond 1980;209:147-51.

3 Yankauer A. Lessons in surgery for the Third World. Am J Public Health 1983;73:1359-60.

4 Samiran. Opinion. Tropical Gastroenterology 1980;1:209-10

Ebong WW. Management of open fractures in remote tropical areas. Trop Doct 1979;9:37.

Sarin SK, Nundy S, Tandon BN. Prospective, randomised, double blind controlled clinical trial of noradrenaline in upper gastrointestinal haemorrhage. Trop Doct (in press)

17 Racoveanu NT. A rational approach to diagnostic radiology. WHO Chron 1983;37:140-2. 